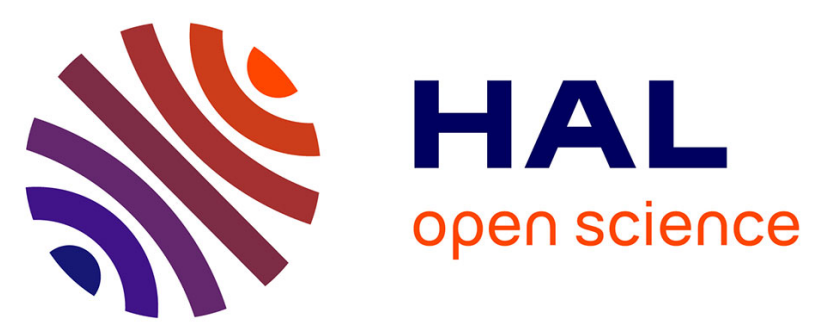

\title{
A Comprehensive Decision Support System for Enhanced Emergency Decision Management and Training
}

Odd Steen, Andrew Pope, Marion Rauner, Nicklas Holmberg, Simon Woodworth, Sheila O'riordan, Helmut Niessner, Karen Neville

\section{To cite this version:}

Odd Steen, Andrew Pope, Marion Rauner, Nicklas Holmberg, Simon Woodworth, et al.. A Comprehensive Decision Support System for Enhanced Emergency Decision Management and Training. 1st International Conference on Information Technology in Disaster Risk Reduction (ITDRR), Nov 2016, Sofia, Bulgaria. pp.183-197, 10.1007/978-3-319-68486-4_15 . hal-03213118

\section{HAL Id: hal-03213118 \\ https://hal.inria.fr/hal-03213118}

Submitted on 30 Apr 2021

HAL is a multi-disciplinary open access archive for the deposit and dissemination of scientific research documents, whether they are published or not. The documents may come from teaching and research institutions in France or abroad, or from public or private research centers.
L'archive ouverte pluridisciplinaire HAL, est destinée au dépôt et à la diffusion de documents scientifiques de niveau recherche, publiés ou non, émanant des établissements d'enseignement et de recherche français ou étrangers, des laboratoires publics ou privés. 


\title{
A Comprehensive Decision Support System for Enhanced Emergency Decision Management and Training
}

\author{
Odd Steen ${ }^{1}$, Andrew Pope ${ }^{2}$, Marion Rauner ${ }^{3}$, Nicklas Holmberg ${ }^{1}$, Simon Wood- \\ worth $^{2}$, Sheila O’Riordan ${ }^{2}$, Helmut Niessner ${ }^{4}$, and Karen Neville ${ }^{2}$ \\ ${ }^{1}$ Department of Informatics, Lund University, Lund, Sweden \\ \{odd.steen, nicklas.holmberg\}@ics.lu.se \\ ${ }^{2}$ Business Information Systems, University College Cork, Cork, Ireland \\ \{a.pope, S.Woodworth, KarenNeville, sheila.oriordan\}@ucc.ie \\ ${ }^{3}$ Department of Innovation and Techn. Management, University of Vienna, Vienna, Austria \\ ${ }^{4}$ School of Business and Economics, University of Vienna, Vienna, Austria \\ \{marion.rauner, helmut.niessner\} @univie.ac.at
}

\begin{abstract}
Emergency decision makers face a challenge taking rapid and highrisk decisions during an emergency situation, especially when the emergency is cross-border and requires multi-agency cooperation. The emergency decision makers use emergency management (EM) system and sometimes decision support systems (DSS) when responding to a crisis. To date the emergency decision makers have not had access to a system that supports them in all facets of the full EM cycle. This paper describes work in progress designing and building a comprehensive system of systems that intend to be that support for emergency decision makers. The system has successfully demonstrated its value from a technical and user perspective. Future tests will demonstrate if it will enhance decision management in reality-based emergency scenarios.
\end{abstract}

Keywords: Emergency Management·Emergency Management Systems·Emergency Decision Making.Emergency Decision Support Systems-Emergency Management Taxonomies.

\section{Introduction}

Large scale emergency situations - be they natural, deliberate or accidental - are inevitable. They do not respect borders, a large number of people and animals, both domesticated and wild, die and the long-term consequences from economic to mental health can for years devastate the affected population.

When emergency decision-takers respond to emergency situations they are sometimes overwhelmed by decision-making [1]. They are required to, based on accessible and available information, make rapid high-risk decision when responding to an emergency situation. Quick decisions regarding allocation of strained resources, prioritizing casualties, while simultaneously trying to contain the level of impact are challenging.

To better manage and respond to emergency situations, emergency decision makers are often supported by disaster management systems that can e.g. provide graphical 
representation of relevant data about the emergency and its consequences. Even if decision support systems (DSS) have been used for emergency management [2, 3] a problem of disaster management systems is the lack of active decision making support needed for effective and efficient emergency responses.

Decision making under emergency situations requires special DSS to be prepared and account for often unforeseen, unique, complex, extreme, and evolving situations and issues that emerge during disasters $[4,5]$. Emergency responders require real-time data and learning/modelling tools to best cope with such situations based on related disaster scenarios. Such a decision support would for instance need to provide capabilities to allocate available and often scarce resources to improve the identification and management of assets during an emergency response [6]. These systems need to integrate multiple components, such as: geographic information systems (GIS), storm tracking tools, damage projection and flooding models, and models for evacuating an affected population [4]. Also, the decision makers need training in emergency management to be better prepared for an emergency situation. Hence, not only is support for decision making in a live situation needed, but also for training of emergency decision makers.

These challenges are addressed by the S-HELP (Securing Health Emergency Learning and Planning) project [7]. With a Design Science Research [8, 9] approach the project researches and develops a comprehensive DSS for end-users to be better prepared, make better decisions, and perform better in emergency situations. The S-HELP DSS will provide support for rapid and effective decision-making for all stages of the emergency management lifecycle [10] from mitigation and preparedness (pre-disaster) to response and recovery (post-disaster).

The challenges for the S-HELP project is to design a DSS that:

- Is flexible enough to integrate with existing legacy systems and tools.

- Offer advanced capabilities and functionalities such as learning approaches based on taxonomies to increase semantic and organizational interoperability of cross-border multi-agency response.

- Facilitate emergency responders to overcome operational inefficiencies and delays regarding coordination and communication to best handle time critical major disaster situations.

Based on this the research question of the paper is: How should a system that meet these challenges be designed? The purpose of the paper is to describe and discuss work in progress designing and building the system of artefacts that will provide a comprehensive support for emergency decision-makers and thus be the DSS that hitherto has been missing.

In section 2, the foundational emergency management taxonomies are discussed. Next, the S-HELP overarching system architecture and interoperability is presented in section 3 , followed by a more detailed description of the major system components in section 4. How the system is tested is discussed in section 5. Finally, the conclusion in section 6 provides policy implications and further research. 


\section{Foundational Taxonomies for Emergency Management}

In the S-HELP project, a DSS is developed for end-users to be better prepared, make better decisions, and perform better in emergency situations. For this reason, an SHELP strategic disaster management wiki to classify disasters (disaster risk, disaster types, extent of event, vulnerability) was created, to illustrate decision making, and to explain the emergency management (EM) environment, emergency management cycle, and the stakeholders involved [11, 12]. This content was expanded by emergency interventions/tasks and emergency resources (emergency responders/skills, equipment and materials, information and data) under consideration of the EU civil protection mechanism (including the EU Civil Protection Modules, [13]). Furthermore, key terms for the three S-HELP disaster scenarios (chemical spill, flooding, biological hazard) were included. The S-HELP strategic disaster management wiki was implemented using the wiki platform of the University of Vienna, Austria which can be accessed via https://wiki.univie.ac.at/display/SHELP/. To enhance semantic and organizational interoperability of end-users [14], the above content was incorporated in the S-HELP DSS as described in sections 3 and 4 .

The strategic disaster management wiki contains main figures, describes terms, links to essential EM organizations, and refers to key literature [11,12]. The second release of the wiki incorporates 951 glossary terms and 33 figures based on 183 references to the literature.

In Fig. 1 the strategic disaster management wiki $(\# 1 ;[11,12])$ represents an essential foundation for the skills taxonomy (\#2; [15, 16]), resources taxonomy (\#3; [17]), and skills/disaster taxonomy (\#4; [18]). These three taxonomies were implemented into the S-HELP DSS as described in sections 3 and 4.

These components of the S-HELP DSS play a key role in training end-users regarding general strategic disaster management for more effective and efficient emergency management, communication, and operation.

The co-operation of different multi-disciplinary emergency responders in disaster management is highly complex in emergency preparedness, response, and recovery. Endusers want to know who of the emergency responders are needed for which emergency interventions/tasks by using what emergency equipment/material in order that emergency management can be better performed and interoperability is increased.

For the skills taxonomy (\#2 of Fig. 1) main emergency interventions/tasks performed by emergency responders using emergency material/equipment and EU Civil Protection Modules were investigated. Based on this, a skills taxonomy was developed by interlinking emergency interventions/tasks and emergency responders/skills [15, 16].

Eleven main interventions were considered including their related tasks: 1) general emergency management, 2) emergency communication, 3) forewarning, 4) evacuation management, 5) impact response, 6) search and rescue, 7) emergency transportation, 8) emergency engineering, 9) emergency shelter, 10) emergency food program, as well as 11) care of vulnerable and secure groups. Emergency responders were classified into: 1) core emergency responders (e.g., government, health care organizations, emergency services), non-core emergency responders (e.g., government, strategic health authori- 
ties, health care organizations, energy providers, food and beverage providers, information and communication services, transportation services, waste disposal services, water and sewerage undertakers), as well as co-operating bodies (military, communities, environmental agencies, media, voluntary sector).

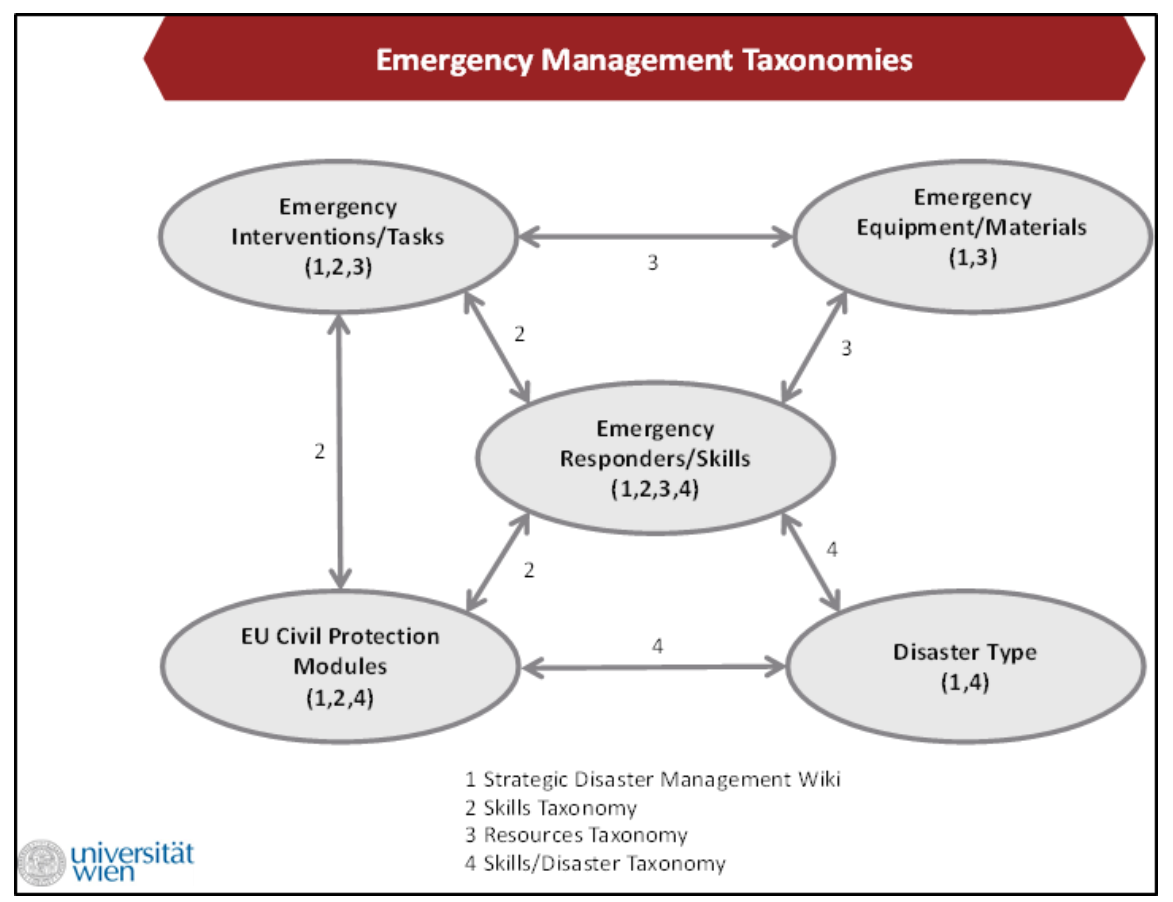

Fig. 1. Foundational emergency taxonomies for the S-HELP DSS

EU Civil Protection Modules contain human and material resources of one or more member states and are able to perform pre-defined tasks in the areas of response [19, 20]: 1) advanced medical post, 2) advanced medical post with surgery, 3) aerial forest firefighting module using airplanes, 4) aerial forest firefighting module using helicopters, 5) chemical, biological, radiological, and nuclear detection and sampling, 6) emergency temporary shelter, 7) field hospital, 8) flood containment, 9) flood rescue using boats, 10) ground forest firefighting, 11) ground forest firefighting using vehicles, 12) heavy urban search and rescue, 13) high capacity pumping, 14) medical aerial evacuation of disaster victims, 15) medium urban search and rescue, 16) search and rescue in chemical, biological, radiological, and nuclear conditions, and 17) technical assistance and support team, as well as water purification).

In the resources taxonomy (\#3 of Fig. 1 [17]) interlinked emergency interventions/tasks and emergency responder/skills (skills taxonomy) to emergency equipment/materials needed including information and data. 
The advantage of the S-HELP DSS to handle three emergency scenarios (chemical spill, flooding, biological hazard) in several example countries (Austria, England, Ireland, Israel, and Northern Ireland) was investigated. It was found that the emergency responders, i.e., core and non-core emergency responders as well as co-operating bodies, responding to a disaster differ according to the underlying disaster type. These were categorized into: 1) natural disasters (biological, cosmological, geophysical, hydro-meteorological), 2) man-made disasters (socio-technical disasters, human conflicts, 3) hybrid disasters (both natural and man-made disasters), and 4) sub-sequent disasters [12]. To enhance interoperability among end-users of different countries, a generic skills/disaster taxonomy which is applicable for any country was developed (\#4 of Fig. 1; [18]). Such differences in emergency responders were illustrated for the three S-HELP scenarios (flooding $->$ natural disaster $->$ hydro-meteorological disaster $->$ hydrological disaster; chemical spill $->$ socio-technical disaster $->$ technological disaster; biological hazard -> natural disaster $->$ biological disaster $->$ epidemic) under consideration of the EU Civil Protection Modules. For the S-HELP flooding scenario, the primary and main core emergency responders are the emergency medical service, the fire brigade, and the police [21]. Several EU Civil Protection Modules are suitable for a flooding which might be called via the Emergency Response Coordination Centre: 1) emergency temporary shelter, 2) flood containment, 3) flood rescue using boats, 4) high capacity pumping, 5) technical assistance and support team, and 6) water purification [18].

\section{The S-HELP DSS Overarching Architecture}

The S-HELP architecture employs a modular design (Fig. 2). This ensures that components in S-HELP are broadly self-contained units that provide tools and decision support functionality around a specific area of the emergency management problem domain. For example, the situation component provides a high level management of the emergency situations modelled within the system.

The knowledge management component provides an interface and functionality relating to the large amounts of documentation and other knowledge assets that exists within the system. While each component on its own provides a level of functionality relating to its 'area of expertise', it is through the connection between components that the full power of the system may be realized.

\subsection{Overview of the S-HELP System Components}

As seen in the systems architecture model (Fig. 2) the comprehensive S-HELP DSS for emergency management and training comprises a collection of artefacts that together form an eco-system of vital components. Each component by itself is less important without the situational operability formed by interlinking the components into a whole system of systems. The overview below summarizes the components and their place and capability in the eco-system. 


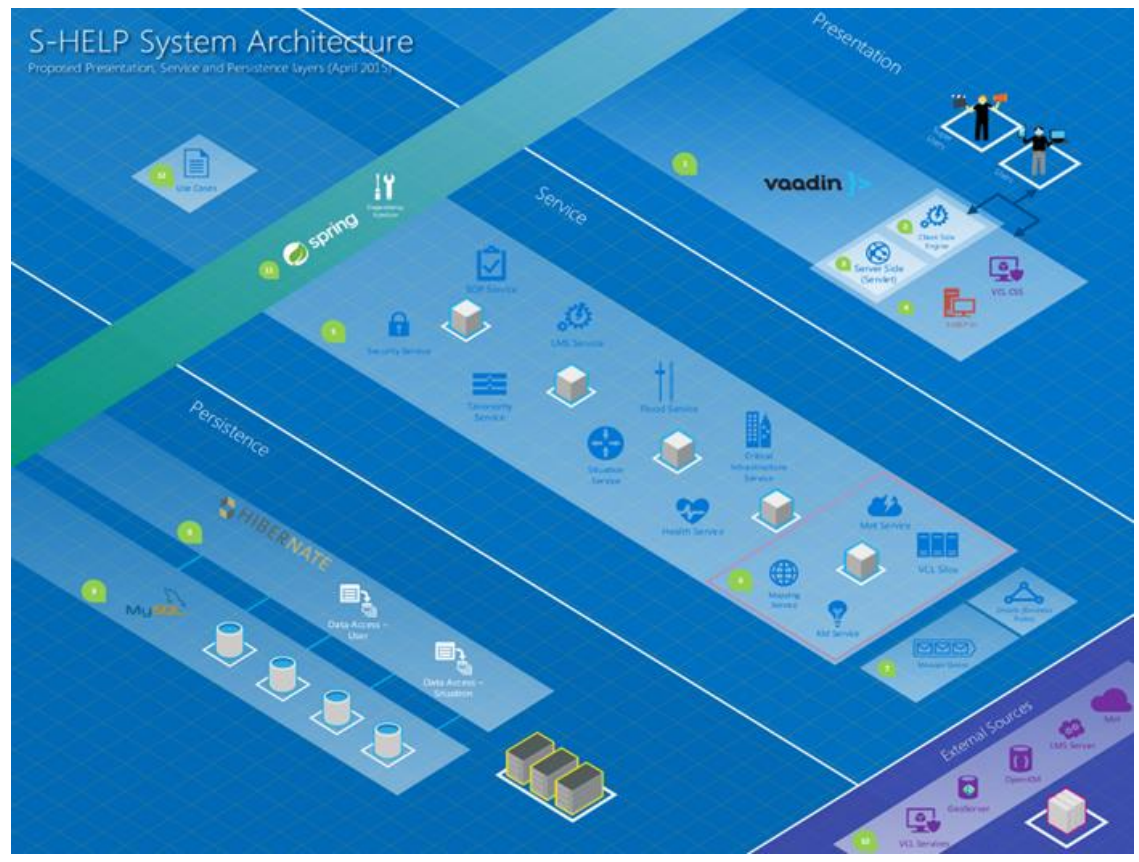

Fig. 2. S-HELP DSS Architecture [22]

Situation Component. Provides an overview of current live situations and associated incidents. Allows user to join situations based on access rights and role.

Current Recognized Situation (CRS) Component. The implementation of an EM information management system. Provides a high level reporting summary of data provided by other S-HELP components. Can be customized to accommodate alternative views and information management frameworks. This component provides the basis for a common operational picture that can be used by all agencies collaborating during an emergency situation.

Logging Component. Provides information managers with a system log of all content generated by S-HELP and external component and traditional data sources (e.g. telephone calls, weather alerts, media reports and e-mails). The information manager can choose data from the logging component and send directly to the CRS component as appropriate.

Learning Management System (LMS) Component. The S-HELP LMS platform provides admin tools, content authoring tools, communication tools, skills and performance management tools, and content management tools. The LMS platform facilitates the "End User Training Programme Concept" incorporating emergency management 
decision making and additional training content. Moreover, the LMS toolset integrates with the S-HELP modular architecture such that training and learning material can be surfaced and shared with other S-HELP components as appropriate.

Knowledge Management System (KMS) Component. A repository of organizational best practices incorporating standard operating procedures (SOPs), existing plans and past response structures, and GIS models. Content can be tagged using the S-HELP taxonomy and location information. As such, relevant content is surfaced automatically based on incident type and location. Surfacing relevant plans, case studies, models, and past incident responses plays a vital role in ensuring that trainees can acquire the experiential knowledge gleaned from past incidents. Moreover, an expert's database will ensure that users can identify, locate and contact those with expertise relevant to the current incident or training scenario

Geographical Information System (GIS) Component. An INSPIRE compliant spatial database management system and front-end incorporating ArcGIS. Provides users with capabilities to visualize critical infrastructure and also assess hazard impact using rich datasets, modelling and spatial analysis tools. The GIS tool can also be used for training, exercises and response. The tool provides real-time visualization of hazards and incident response. The interactive features allow for end users to engage with the data for decision making and coordination purposes. The ability to import and export external models and shapes enhances multiagency coordination through the sharing of incident-specific critical information and data. Likewise, previous incidents and models can be geocoded such that relevant models are surfaced to the user based on the incident type and incident locale.

Twitter Component. The twitter component gathers information from the social media service Twitter. S-HELP users can search for tweets statically using location data (input manually or derived from location of current situation). Relevant tweets are displayed on a map and clustered accordingly. Relevant user information and tweet content will be displayed. Additionally, trending topics can be requested for given locations. A streaming service that reports and displays new tweets that relate to topics of given S-HELP users' preferences is also available. Using topic filters, the twitter module will display new tweets that meet the S-HELP users' filter queries, and it will do so in real time.

\section{Major Backbone System Components}

Essential for emergency decision making and training using the S-HELP DSS is the provision of generic and situational data consistent with the taxonomies (cf. section 2), interlinked emergency management documents and Standard Operating Procedures (SOP) documents, and geographic emergency data. Four major components of the SHELP DSS form a back-bone infrastructure: the Knowledge Management System 
(KMS) component, the Repository for Data Sets component, the Document Management System (DMS) component, and the Current Recognized Situation (CRS) component.

\subsection{Knowledge Management System (KMS)}

A key enabler of the S-HELP DSS approach is the creation of a Knowledge Management System to create, store and transfer the knowledge assets that comprise the experiential knowledge of emergency management practitioners. This will facilitate individual and inter- and intra-group learning in crisis management decision-making. The creation of a Learning and Knowledge Management Systems (LKMS) necessitates the integration of a Learning Tool-set and Knowledge Management System.

The LKMS comprises a repository for data sets realized as a relational database that stores emergency and disaster typology data consistent with the Emergency Management Taxonomies (cf. section 2). Furthermore, it is integrated with a knowledge repository (Open KM) that supports the storage and transfer of knowledge assets in the form of standard operating procedures, emergency plans, business process models, expert yellow pages and other relevant documents. This powerful knowledge repository has been integrated with a learning platform (Moodle), and learning tools, that facilitate the training of key emergency management personnel.

\subsection{Repository for Data Sets Component}

Viewed from an enterprise architecture perspective [23, 24] the taxonomies discussed in section 2 identify the inventory (row 1, column 1 in the Zachman Framework for EA v. 3.0) for the S-HELP LKMS, answering to the requirements set by the intentions (row 1, column 6 in the Zachman Framework for EA v. 3.0). Thus, the taxonomies specify the business concepts about which data needs to be managed in order for the S-HELP system to be able to fulfill the goals and intentions set by the planners of the system.

Based on the inventory identification the inventory specification (row 2, column 1 in the Zachman Framework for EA v. 3.0) was digitally transformed [25] into a Unified Modeling Language (UML) conceptual model (see Fig. 3).

The conceptual model was transformed into a relational logical model (see Fig. 4) for the data set repository, and then further to a physical data model implemented in MySql Server 5.6.

Through this digital transformation, the data repository partly automates and digitalizes the foundational emergency management taxonomies.

The data set repository makes it possible to store and retrieve information about e.g. what kind of resources a generic emergency responder uses for one or more emergency tasks in responding to a specific type of emergency (e.g. a flood), as discussed in section 2 (see Fig. 5 and Fig. 6).

When the data set repository is populated with generic and specific, real incident data it will be a knowledge base of both general and situated emergency information that could be queried by emergency decision makers during a live incident or fed as 
data into emergency responder training scenarios used for the Learning and Knowledge Management System (LKMS).

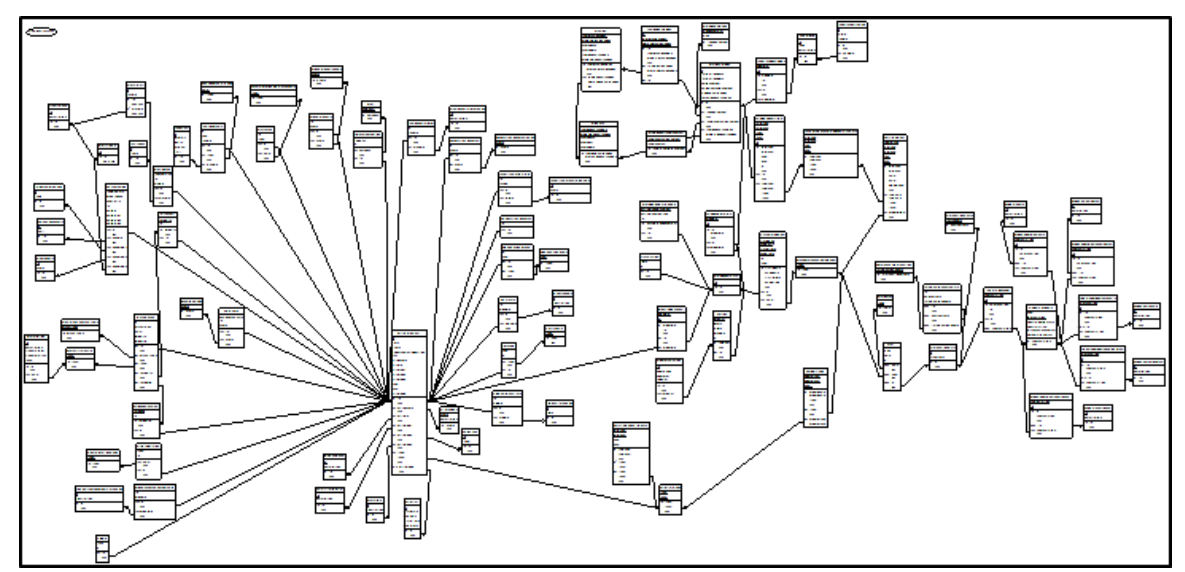

Fig. 3. S-HELP data repository conceptual model [26, 27]

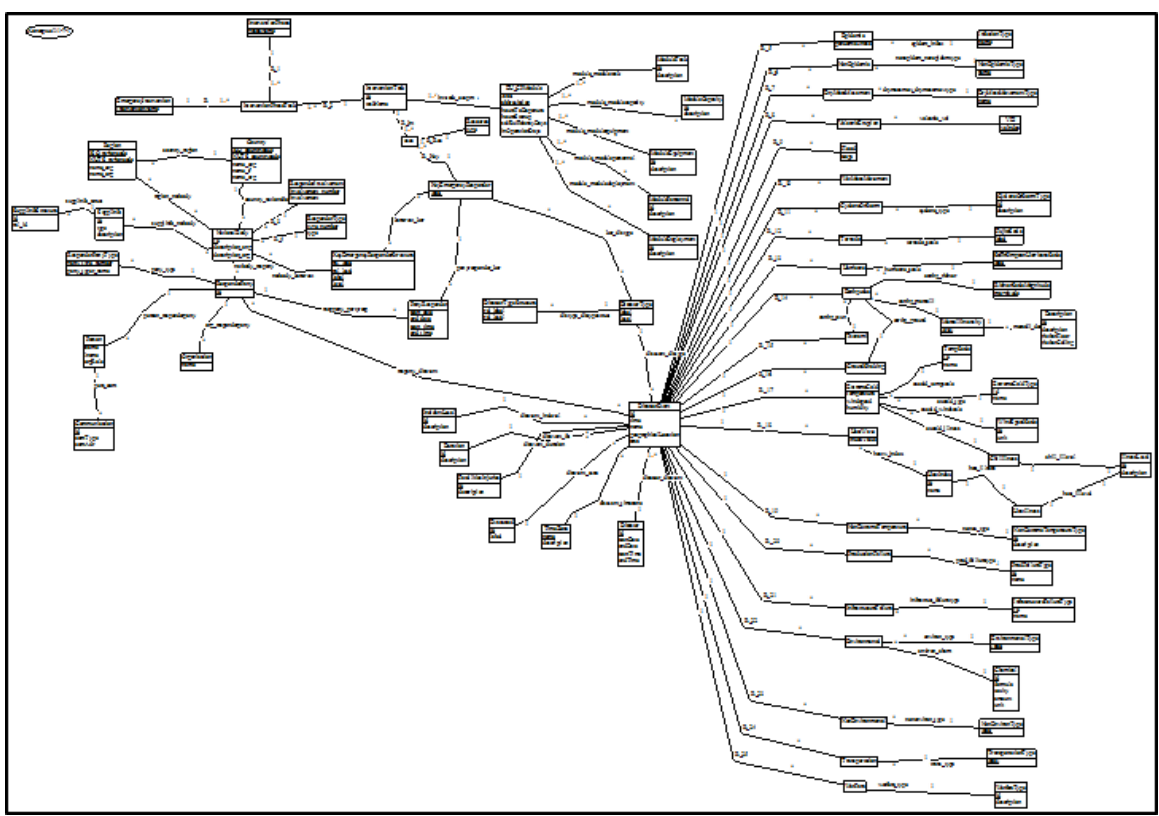

Fig. 4. S-HELP data repository logical model $[26,27]$ 


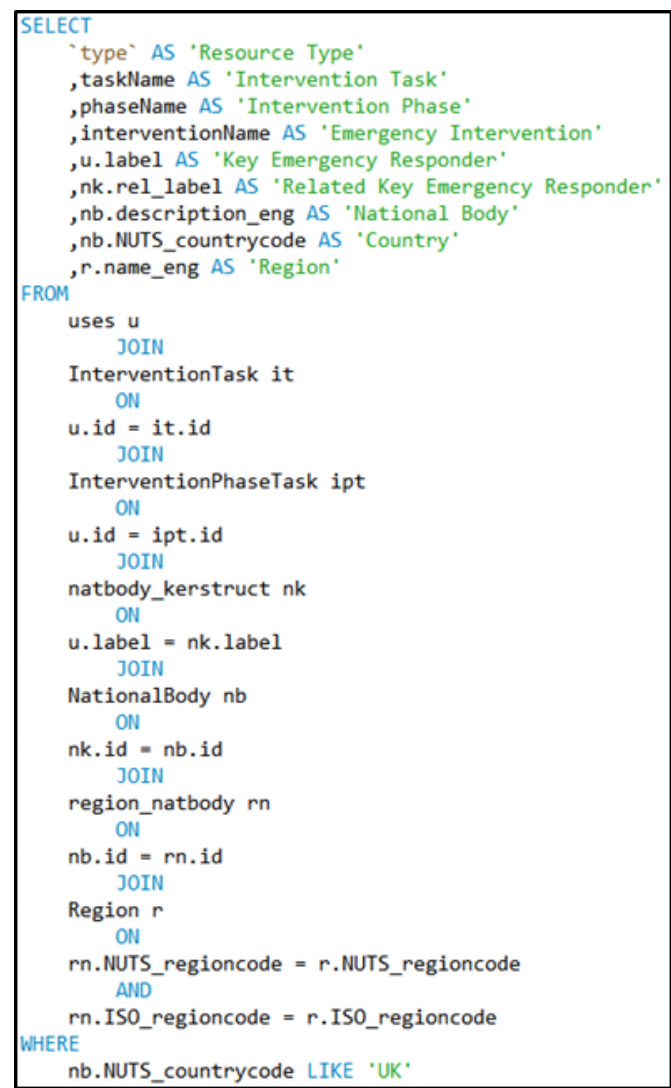

Fig. 5. An example data repository query in S-HELP

The output in Fig. 6 shows that in the 'London' region of the country 'UK' the 'County Police' acts as the generic key emergency responder (KER) 'Police', using e.g. the generic resource type 'Checklists/Plans' while performing the 'Evacuating' Intervention Task of the 'Evacuation Management' Emergency Intervention type in the 'Response' Intervention Phase to manage an emergency incident.

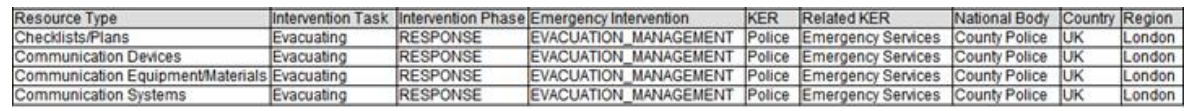

Fig. 6. Output from the query in Fig. 5 (only a few lines showing)

As each country have built up their own and nationally tailored organization and structure of emergency management, it is important that total flexibility is guaranteed in associating a national responder body to a generic responder in the taxonomy. 
The Party Pattern [28] made it possible to record that a responder party (individual, organisation, or both) assumes the role of a national responder for a certain unique disaster event. The responder party type also assumes the responsibilities of a generic key emergency responder for a determined period. Modelling principles from [23] made it possible to manage relations between super and sub entities through type entities, as well as maintaining dynamic hierarchical structures between data elements reflecting the taxonomies.

Combining all these connections gives the possibility to record what person and/or organization that acts as a national responder for a certain disaster event and also what person and/or organization that acts as a key emergency responder for the same disaster event (cf. Fig. 4).

Document Management System (DMS) Component. Open KM (OKM) was configured to fulfill the document management functionality of the LKMS. OKM provides managerial capabilities such as tagging, reading, writing, and storing useful emergency intervention documentation. Hence, OKM can facilitate individual and group learning, and the management (sharing/transfer/creation/use and control) of end user knowledge as part of the LKMS.

The document structure implemented in OKM (see Fig. 7) is in accordance with the taxonomies discussed in section 2. Thus the structure of the data repository and the document management system are synchronized to accommodate easy integration of data sources in the LKMS.

The KM is incorporated into the S-HELP KMS component using REST (REpresentational State Transfer) services and also provides facilities to build work flows in the jBPM Business Process Management suite. Based on the taxonomy in project deliverable D2.4 [16] a number of Business Process Model and Notation (BPMN: [29]) 2.0 models were developed in the project [26].

\subsection{Current Recognized Situation Component}

One important information management capability of the S-HELP system is the Current Recognized Situation (CRS) component. It was designed based on a work-flow identified by the S-HELP end-user group and incorporates lessons learned from Irish Framework for Emergency Management [30]. The CRS module provides an electronic implementation of current manual information management systems which often incorporate the use of whiteboards. However, the system goes beyond merely providing a digital implementation of manual information management techniques. Current manual EM information management systems are highly dependent on hand written input of information by qualified "Information Managers" on a single set of on-site whiteboards and markers. When the whiteboards run out of space for new entries, a picture is taken and the content is erased. If there are multiple incidents associated with a single emergency situation, then boxes are informally drawn onto the corners of relevant whiteboards. 


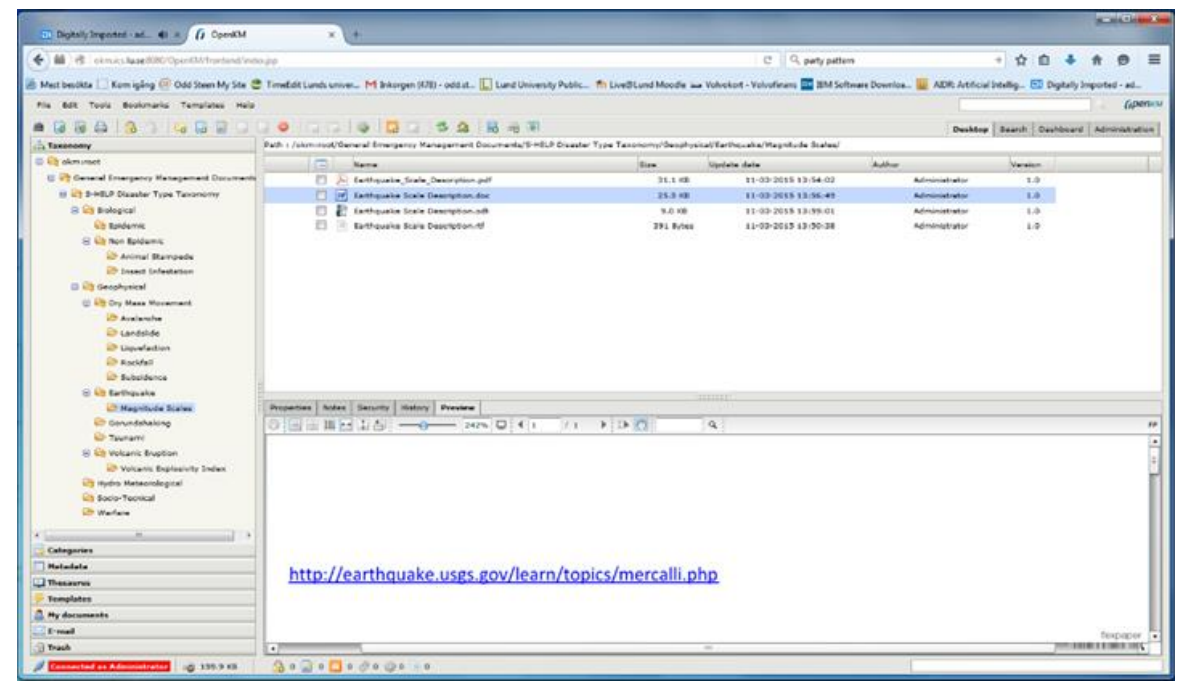

Fig. 7. Document structure in OKM

\subsection{Integration with Taxonomy}

Beyond merely providing a means of facilitating manual data entry the development team has also been working on automatically generating content for the CRS panels based on the taxonomy and data modelling efforts. Unique Java classes have been created based on the collective output of the University of Vienna's Emergency Management Taxonomy and Lund University's Object Model representation. Resource entries can be automatically generated based on queries executed on different disaster types upon instantiation. For example, when an incident is created with a specific disaster type (e.g. flood), queries can be executed to derive a list of possible intervention tasks associated with the disaster type (e.g. evacuating) and consequent responder and resources required to fulfil the interventions (e.g. police and evacuation vehicles) will be identified. Once identified, new CRS entities will be created and added to the Resources panel automatically. Moreover, the taxonomy can be used to generate sample response structures and populate generic action lists based on best practices, thus providing an important decision support and training function. Furthermore, past responses, gleaned from the KMS, can be displayed to leverage the experiential knowledge of historical incidents.

\section{$5 \quad$ Testing of the S-HELP DSS}

The S-HELP system adheres to the S-HELP Quality Manual which specifies a valid test suite for any software artefact. For the S-HELP project, the test suite must cover all documented requirements of all types, it must fit into the accepted types of software tests (e.g., unit, integration, system), it must be reviewed and all specified tests must 
be executed, passed and reviewed. In practice, three different test types have been executed.

Unit Tests target a specific class. Objects are mocked and injected as necessary to test that class in isolation from other classes. The Maven build and dependency manager is used to drive test suites; such testing is tightly integrated with the build process. This is expected in an agile test environment. Unit Testing is fully automated.

Integration Tests are designed to test the interaction of a specific class with other classes or with a remote service or database. In all other respects Integration Tests are similar to Unit Tests. Like Unit Tests they can be run automatically as part of the Maven build process. Similarly test results are reported automatically.

User interaction and System Tests are manual in nature. User Interaction tests follow the use cases laid out for the S-HELP system and are documented in Excel spreadsheets. Failing tests are logged as bugs in the JIRA Software reporting system (https://www.atlassian.com/software/jira). The focus of these tests is to ensure that the User Interface behaves as designed and is productively useful to an emergency command center operator.

System tests to date have been limited in scope. So far the S-HELP build/deployment process has been tested on multiple operating systems on Irish sites and also in a site in Austria. The test results demonstrate the deployability of S-HELP. Furthermore, the target platforms are diverse in terms of architecture and processing power (OS X and Ubuntu on Intel, Debian on ARM). These tests have demonstrated consistency of system operation and user experience across diverse platforms.

\section{Conclusion}

The S-HELP DSS will facilitate a better coordination and communication of multiagencies' emergency responders during major disasters to overcome operational inefficiencies and delays. This is especially essential and even crucial in times of increased susceptibility of our society to hazards and other threats caused by climate change, demographical change, political and economic instability, urbanization, migration, and flow of refugees (cf., e.g., [31, 32]).

The work on designing and building the S-HELP DSS is ongoing and tests carried out so far are promising. Work to be done is to test and demonstrate that the S-HELP DSS system of systems will provide the necessary emergency decision and training support for emergency decision makers. A series of three scenarios will be used to test this. These scenarios are being prepared to test incident intelligence, multi-agency response, what-if modelling, GIS capabilities, learning tool sets and post action evaluation. The scenarios will be used to test the system in a realistic operating environment 
across different disaster types. The scenarios comprise cross-border chemical explosion, biological hazard and widespread flood events. Future papers and articles will report on the outcome of these tests.

\section{Acknowledgments}

This project is funded by the European Union's Seventh Framework Programme for research, technological development and demonstration under grant agreement $\mathrm{N}^{\circ} 607865$.

\section{References}

1. Alexander, D.: Principles of emergency planning and management. Oxford University Press, Oxford ; New York (2002).

2. Egli, D.S.: Beyond the storms: Strengthening preparedness, response, \& resilience in the 21 st century. Journal of strategic security 6, pp. 32. (2013).

3. Whybark, D.C.: Co-creation of improved quality in disaster response and recovery. International Journal of Quality Innovation 1, 1-10. (2015).

4. Tufekci, S.: An integrated emergency management decision support system for hurricane emergencies. Safety Science 20, 39-48. (1995).

5. Turoff, M., White, C., Plotnick, L., Hiltz, S.R.: Dynamic emergency response management for large scale decision making in extreme events. Proceedings of the 5th International ISCRAM Conference, pp. 462-470. ISCRAM Washington, DC, USA (2008).

6. Kondaveti, R., Ganz, A.: Decision support system for resource allocation in disaster management. Engineering in Medicine and Biology Society, EMBC 2009. In: Annual International Conference of the IEEE, pp. 3425-3428. IEEE (2009).

7. Securing Health Emergency Learning Planning, S-H.E.L.P., Collaborative Project FP7SEC-2013-1, Project no. 60786. European Union (2014).

8. Gregor, S.: Building Theory in the Sciences of the Artificial. In: Proceedings of the 4th international conference on design science research in information systems and technology. $\operatorname{ACM}(2009)$.

9. Gregor, S., Jones, D.: The anatomy of a design theory. Journal of the Association for Information Systems 8, p. 312. (2007).

10. Alexander, D.: Principles of emergency planning and management. Oxford University Press, Oxford, New York (2012).

11. Rauner, M., Pope, A., Niessner, H., Neville, K., Sasse, L., Tomic, K., O’Riordan, S.: Decision Support for Strategic Disaster Management: First Release of a Wiki. In: Dawid, H., Doerner, K., Feichtinger, G., Kort, P.M. (eds.) Dynamic Perspectives on Managerial Decision Making - Essays in Honor of Richard F. Hartl. Springer, Heidelberg, Germany (2016).

12. University of Vienna, Austria: Glossary of terms and definitions and common grounds and standards for interoperability. Deliverable No. 2.1 (2014).

13. European Commission: Commission Implementing Decision of 16.10.2014 laying down rules for the implementation of Decision No 1313/2013/EU - Annex II- C (2014) 7489 final. European Commission, EC (2014).

14. Vernadat, F.B.: Enterprise modelling and integration. Springer, New York (2003). 
15. Rauner, M., Pope, A., Niessner, H., Neville, K., Sasse, L., Tomic, K., O'Riordan, S.: Improving Decision Making in European Disaster Management: A Skills Taxonomy of Main Emergency Responders Needed for Key Emergency Interventions. Working Paper (2016).

16. University of Vienna, Austria: Draft Skills Taxonomy Template. Deliverable No. 2.4 (2015).

17. University of Vienna, Austria: Draft Rescources Taxonomy Template. Deliverable No. 2.7 (2015).

18. University of Vienna, Austria: S-HELP Interoperability Standard. Deliverable No. 2.11 (2016).

19. European Commission: Decision 2010/481/EU Annex II, Euraton. Official Journal of the European Union 7 (2010).

20. European Parliament and the Council: Decision No 1313/2013/EU. Official Journal of the European Union (2013).

21. FLOODsite: Review Report of Operational Flood Management Methods and Models. FLOODsite http://www.floodsite.net/html/partner_area/project_docs/Task17_report_M17_ 1review_v1_1.pdf (2007).

22. Neville, K., O’Riordan, S., Pope, A., Rauner, M., Maria, R., Madden, M., Sweeney, J., Nussbaumer, A., McCarthy, N., O‘Brien, C.: Towards the development of a decision support system for multi-agency decision-making during cross-border emergencies. Journal of Decision Systems 25, 381-396 (2016).

23. Finkelstein, C.: Enterprise Architecture for Integration: Rapid Delivery Methods and Technologies. Information Engineering Services Pty Ltd, Australia (2015).

24. Zachman International®, Inc., https://www.zachman.com/images/ZI_PIcs/ZF3.0.jpg

25. Majchrzak, A., Markus, M.L., Wareham, J.: Designing for Digital Transformation: Lessons for Information Systems Research from the Study of ICT and Societal Challenges. MISQ 40, 267-277 (2016)

26. Lund University, Sweden: Learning and Knowledge Management System (LKMS). Deliverable No. 4.4 (2015).

27. Lund University, Sweden: Repository for Data Sets. Deliverable No. 4.2 (2014).

28. Fowler, M.: Analysis patterns: reusable object models. Addison Wesley, Menlo Park, Calif. (1997).

29. Object Management Group: Business Process Model and Notation (DMN) Version 2.0. (2011).

30. National Steering Group, Principal Response Agencies, MEM: Framework for Major Emergency Management (2006).

31. Coppola, D.P.: Introduction to international disaster management. Butterworth-Heinemann, Boston (2011).

32. Neville, K.M., Doyle, C., Mueller, J., Sugrue, A.: Supporting Cross Border Emergency Management Decision-Making. In: ECIS 2013 Proceedings, pp. 1-7 (2013). 